\section{Perspectiva de alimentação infantil obtida com gestantes atendidas em centros de saúde na cidade de São Paulo}

\section{Infant feeding expectations according to the pregnant women seen at the healthcare center in the city of São Paulo}

Sueli Aparecida Moreira Takushi 1 Ana Cristina d'Andretta Tanaka 2 Paulo Rogério Gallo 3 Ana Maria Bara Bresolin 4

1 Departamento de Saúde Materno-Infantil. Faculdade de Saúde Pública. Universidade de São Paulo. Av. Dr. Arnaldo, 715, Sala 218. São Paulo, SP, Brasil. CEP: 01.246-904 E-mail: suelimoreira@yahoo.com.br

4 Secretaria Municipal da Saúde. São Paulo, SP, Brasil

\begin{abstract}
Objectives: to obtain information from pregnant women on how they planned to feed their infants during the first year of life.

Methods: cross sectional study of the data obtained through structured questionnaires, filled by means of individual interviews with 164 pregnant women assisted by prenatal clinics in Outpatient Centers in the city of São Paulo. Statistical ChiSquare test was used to determine association between age, school level, parity and knowledge on the variety of fruits, vegetables and meats available.

Results: all women knew at least one type of fruit and vegetable while $20 \%$ of the women did not intend to offer vegetables. Significant statistical results between age, school level, parity and knowledge on the variety of fruits and vegetables available were not determined. The most rejected food, according to the mothers were fish (85.4\%) and liver (82.3\%). Many myths were determined related to the iron content of food.

Conclusions: the intention of offering food to children under six months old was frequent. The value of discussing the transition of infant feeding during prenatal care was determined as well.
\end{abstract}

Key words Feeding, Criança, Breast feeding, Weaning

\section{Resumo}

Objetivos: conhecer a dieta infantil pretendida por gestantes para o primeiro ano de vida.

Métodos: estudo transversal cujos dados foram obtidos em formulário estruturado, aplicado durante entrevista individual com 164 gestantes, usuárias da Assistência pré-natal, de centros de saúde da cidade de São Paulo. Para análise estatística foi aplicado teste do $\chi^{2}$ para verificar associação entre idade, escolaridade, paridade e conhecimento de variedade de frutas, legumes, verduras e carnes.

Resultados: todas as mulheres conheciam pelo menos uma variedade de fruta e de legume, enquanto que $20 \%$ delas não pretendiam introduzir verduras. Não foram obtidos resultados estatisticamente significantes entre idade, escolaridade, paridade e conhecimento de variedade de frutas e de legumes. Foram obtidos resultados estatisticamente significantes entre idade, paridade e conhecimento de variedade de verduras e de carnes. Os alimentos mais rejeitados, na intenção materna, foram o peixe $(85,4 \%)$ e o fígado (82,3\%). Foram constatados mitos em relação ao teor de ferro de alimentos.

Conclusões: a intenção de oferecer alimentos à criança em idade inferior ao sexto mês de vida foi freqüente. Reafirma-se a importância de se discutir a transição alimentar infantil durante a assistência prestada à mulher.

Palavras-chave Alimentação, Criança, Aleitamento materno, Desmame 


\section{Introdução}

Na compreensão do saber popular sobre a alimentação infantil convém considerar o fato de que as mulheres sempre participaram da construção deste senso comum ao longo da sua trajetória. Na elaboração das práticas alimentares infantis atuam fatores socioeconômicos, culturais, geográficos, demográficos, psicológicos e resultantes da interação mãe e filho, que refletem no interesse materno e na qualidade da alimentação infantil.

No Brasil, o modo de alimentar as crianças decorre da história política, econômica e cultural, incluindo o tipo de colonização ocorrida, quando se conjugaram hábitos da cultura indígena, européia e africana. 1 Entre os colonizadores europeus não existia qualquer distinção entre a dieta do adulto e da criança e a instituição de papas na dieta infantil ocorreu com a presença da mulher africana. ${ }^{2}$ As relações comerciais com a Europa devido à exportação do açúcar favoreceram a incorporação da Puericultura dando início ao processo de desapropriação do saber popular sobre alimentação infantil pelas ciências médicas. A medicalização foi uma estratégia de controle sócio-político das formulações populares que se iniciou pelo cuidado da criança, prosseguindo com a apropriação do corpo feminino e de tudo que nele ocorre. $3-5$

A amamentação foi destituída da população, impulsionada pela medicina, e contou com o poderoso estímulo da indústria de leite em pó, em consonância à rápida urbanização e ao intenso ingresso da mulher no mercado de trabalho. Nesse cenário, o desmame precoce atuou associado a outros fatores para elevar a taxa de mortalidade infantil no período de 1961 a 1973 , em até $45 \% .6 \mathrm{Na}$ década de 80 criou-se o Programa de Atençao Básica a Saúde da Mulher (PAISM) com a proposta de integralidade da mulher, considerando-a em todas as fases da vida, com suas especificidades sociais, psicológicas, biológicas e da saúde. ${ }^{7}$

A influência da Puericultura se deu até 1946, quando ocorreu a chegada das escolas americanas e a assistência passou a ser regulada pelos organismos internacionais por meio de normatizações, métodos vigentes até os dias atuais. 3,4 Atualmente, dentre as normativas dirigidas às mulheres, o incentivo ao aleitamento materno exclusivo até seis meses de vida, com a introdução de alimentação complementar, sem interromper a amamentação, consiste em recomendação mundial de saúde pública na redução da morbi-mortalidade infantil. 8,9

A partir dos seis meses de idade, a criança passa a apresentar maturidade fisiológica (renal e diges- tiva) 10 e se torna apta a receber boa parte de alimentos de composição e consistência diferentes do leite materno, 10 ao mesmo tempo em que fica vulnerável à deficiência em ferro, 11,12 em decorrência do crescimento acelerado que apresenta. ${ }^{11}$ Incluir alimentos que sejam fontes de ferro heme, biologicamente mais disponível após proteólise da hemoglobina, 13 é prioridade a partir dos seis meses de vida.11,12 A alimentação complementar deve fornecer variedade de alimentos nutrititivos, $10 \mathrm{de}$ boa qualidade microbiológica, 8,9 de apropriada digestibilidade, 14 de baixa alergenicidade, 15 isentos de substâncias impróprias ao consumo no primeiro ano de vida, ${ }^{16,17}$ que se iniciem sob consistência semi-sólida. ${ }^{18}$

Antes dos seis meses, a introdução de alimentos tende a substituir o aleitamento materno, não conferindo nenhuma vantagem para o crescimento infantil, quando comparada à amamentação exclusiva, 8,9 além de se manter relacionada a uma série de eventos prejudiciais à saúde da criança que afetam, principalmente, seu sistema gastrointestinal.19-21 Dietas substitutas à base de leite de vaca têm sido associadas à ocorrência de ferro-deficiência e anemia no primeiro ano de vida. 22

A introdução precoce de alimentos tem sido atribuída à falta de informação das mulheres sobre a composição do leite materno, 23 enquanto a escolaridade materna tem sido apontada como favorável à obtenção de conhecimento durante a assistência prénatal. 24 A presença de filho anterior pode representar maior oportunidade de aprender pela prática e pelo conhecimento obtido durante orientação pediátrica. $\mathrm{O}$ aprendizado sobre dieta infantil pode ser adquirido pela experiência de vida e de observação de alguém da família preparando alimentos às crianças pequenas. Vieira et al. 25 verificaram que filhos de mães adolescentes ingerem significativamente menos carne que os filhos de mães adultas. A seleção alimentar pode ser guiada pelas cores dos alimentos 26 e influenciada pela exposição materna e familiar aos meios de comunicação, pelas marcas e embalagens.

Diante disso, realizou-se o presente estudo com o objetivo de caracterizar a alimentação complementar pretendida por gestantes para ser introduzida no primeiro ano de vida, tendo em vista que aspectos específicos da introdução precoce de alimentos sem apoio técnico representam importante problema de Saúde Pública. 


\section{Métodos}

Estudo transversal envolvendo gestantes que freqüentaram a assistência pré-natal do Centro de Saúde-Escola Barra Funda e do Centro de SaúdeEscola Paula Souza, ambos localizados na região central da cidade de São Paulo, Brasil. A população atendida caracteriza-se por mulheres que moram ou que trabalham nas proximidades dos Centros de Saúde. A identificação socioeconômica foi obtida a partir dos relatos das mulheres, sendo em sua grande maioria empregadas de serviços domésticos e de oficinas de costuras. Devido à escassez de gestantes, em razão dos Centros de Saúde localizarem-se em região de baixa fecundidade, optou-se por agrupar a demanda de gestantes atendidas nos dois Centros, no período de março a agosto de 2002, totalizando uma amostra de 164 mulheres brasileiras. Em razão da diversidade cultural dos hábitos alimentares, as gestantes estrangeiras foram excluídas da amostra.

O estudo foi submetido e aprovado pelo Comitê de Ética da Faculdade de Saúde Pública da Universidade de São Paulo em 12 de setembro de 2001; o contato com as usuárias foi autorizado pela direção dos Centros de Saúde e, mediante cada candidata, procedeu-se à leitura prévia e assinatura do termo de consentimento livre e esclarecido elaborado de acordo às Normas e Diretrizes Éticas da Resolução do Conselho Nacional de Saúde 196 de 1996 do Ministério da Saúde.

Os dados foram obtidos por meio de formulário estruturado sobre a intenção de oferta da alimentação complementar, aplicado durante entrevista, realizada unicamente pela pesquisadora com cada uma das 164 gestantes usuárias. Os dados foram registrados em formulários e transferidos para um banco de dados. Empregou-se o programa Epi-info 2002 para a realização dos testes estatísticos do $\chi^{2}$, respeitando-se um erro alfa de 0.05 .

As variáveis de identificação correspondem à idade, classificada em adolescentes com 15-19 anos e adultas com 20 a 43 anos; à escolaridade que foi agrupada em anos de estudo e à paridade, avaliada pela presença ou ausência de filhos anteriores.

As variáveis da alimentação complementar foram organizadas segundo a ordem de intenção de oferta dos alimentos, verificada pelo pré-teste do formulário com outras gestantes, em líquidos: água e chá, suco de frutas e leite de vaca em pó e fluido; semi-sólidos: frutas, legumes e verduras; fontes de ferro heme: fígado, carne, frango, peixe e de ferro não-heme: feijão e ovos.

Foram realizados testes estatísticos entre idade, escolaridade e paridade em relação ao conhecimento de variedade de frutas, legumes, verduras e carnes. Os dados foram analisados a partir da somatória de respostas ao grupo de alimento pretendido. Admitiuse como insatisfatório o conhecimento de até uma variedade de alimento em relação ao conhecimento de duas ou mais variedades do mesmo alimento.

\section{Resultados}

Observou-se que na população $83,6 \%$ eram adultas com idade entre 20 a 43 anos, sendo que a proporção de $45,1 \%$ tinha entre 9 a 13 anos de estudo e pouco mais da metade $(52,4 \%)$ eram nulíparas ou não tinham filho anterior (Tabela 1). As mulheres fazem parte da classe trabalhadora de menor condição socioeconômica.

Tabela 1

Perfil de gestantes usuárias de Centros de Saúde. São Paulo, Capital, 2002.

\begin{tabular}{lrc}
\hline & $\mathrm{N}=\mathbf{1 6 4}$ & $\%$ \\
\hline Idade (em anos) & & \\
$\quad 15$ a 19 & 137 & 16,4 \\
20 a 43 & & \\
Escolaridade (em anos) & 32 & 19,6 \\
1 a 4 & 58 & 35,4 \\
5 a 8 & 74 & 45,1 \\
9 a 13 & & \\
Paridade & 86 & 52,4 \\
Sem filho & 78 & 47,6 \\
Com filho(s) & & \\
\hline
\end{tabular}

Conforme Tabela 2, para os primeiros cinco meses de vida, a oferta de água e chá foi pretendida por $71,3 \%$ das gestantes; a oferta de suco de frutas foi admitida por $46,3 \%$ de mulheres, e $39 \%$ delas se mostraram favoráveis à oferta de leite de vaca em pó. A intenção de introduzir leite de vaca fluido foi mais freqüente após o $10^{\circ}$ mês de vida (Figura 1).

Verificou-se que as frutas e os legumes foram os alimentos mais populares na opinião materna. Todas elas pretendiam incluí-los na dieta da criança, inexistindo desconhecimento ou recusa de intenção em ofertá-los (Tabela 2).

Constatou-se associação estatisticamente significante entre idade, paridade e conhecimento de variedade de verduras e de carnes $(p<0,05)$ (Figuras 2 e 3$)$. 
A escolaridade não se mostrou estatisticamente significante em relação ao conhecimento de nenhuma das variedades de alimentos estudadas $(p>0,05)$.

$\mathrm{O}$ frango e a carne foram as fontes de ferro heme de maior interesse (Tabela 2). O peixe e o fígado foram os alimentos mais rejeitados. De acordo com a Tabela 2, 85,4\% das gestantes admitiram não ter interesse pela oferta de peixe na dieta infantil, enquanto o fígado obteve $82,3 \%$ de recusa. A introdução de carnes, de um modo geral, foi prevista para ocorrer por volta do sexto mês de vida, porém para $31,1 \%$ das mulheres a carne não será incluída na dieta da criança (Tabela 2), enquanto que a oferta de ovos e feijão foi pretendida para o primeiro ano de vida, conforme Figura 1.

\section{Tabela 2}

Perspectiva de freqüência da introdução de alimentos no primeiro ano de vida, obtida com gestantes de Centros de Saúde. São Paulo, Capital, 2002.

Idade pretendida em meses (\%)

\begin{tabular}{|c|c|c|c|c|c|}
\hline & $\leq 5$ & 6 & $\geq 7$ & Não sabe & Não vai dar \\
\hline \multicolumn{6}{|l|}{ Alimentos líquidos } \\
\hline Água e chá & 71,3 & 7,9 & 1,2 & 2,4 & 17,1 \\
\hline Suco de Iaranja & 46,3 & 36,0 & 9,8 & 2,4 & 5,5 \\
\hline Leite de vaca em pó & 39,0 & 33,5 & 19,5 & 4,3 & 3,7 \\
\hline Leite de vaca fluido & 4,9 & 14,6 & 72,0 & 6,1 & 2,4 \\
\hline \multicolumn{6}{|l|}{ Alimentos semi-sólidos } \\
\hline Frutas & 34,7 & 35,4 & 29,9 & 0 & 0 \\
\hline Legumes & 32,9 & 44,5 & 22,6 & 0 & 0 \\
\hline Verduras & 12,2 & 28,0 & 27,4 & 12,2 & 20,1 \\
\hline \multicolumn{6}{|c|}{ Alimentos que são fonte de ferro } \\
\hline \multicolumn{6}{|c|}{ Heme } \\
\hline Frango & 18,9 & 32,9 & 31,1 & 1,8 & 15,2 \\
\hline Carne & 16,5 & 25,0 & 25,6 & 1,8 & 31,1 \\
\hline Fígado & 4,9 & 6,1 & 4,9 & 1,8 & 82,3 \\
\hline Peixe & 3,0 & 3,0 & 6,7 & 1,8 & 85,4 \\
\hline \multicolumn{6}{|l|}{ Não-heme } \\
\hline Ovos & 7,9 & 14,0 & 62,8 & 8,5 & 6,7 \\
\hline Feijão & 2,4 & 11,6 & 84,1 & 1,8 & 0 \\
\hline
\end{tabular}


Perspectiva de introduzir alimentos na dieta infantil obtida com gestantes de Centros de Saúde. São Paulo, Capital, 2002.
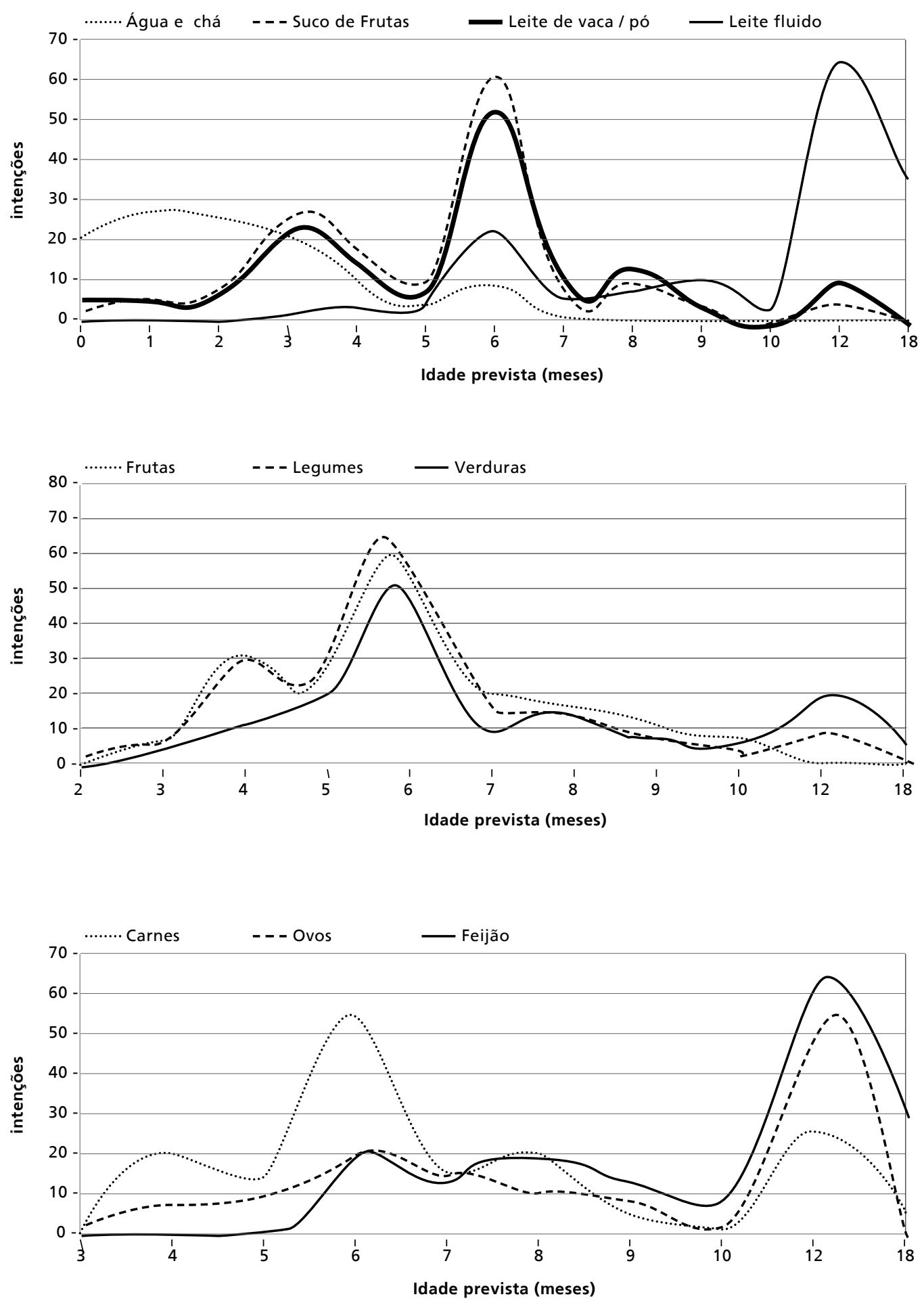
Conhecimento de variedade de alimentos segundo paridade de gestantes de Centros de Saúde. São Paulo, Capital, 2002.

Conhecimento de variedade de carne segundo a paridade materna

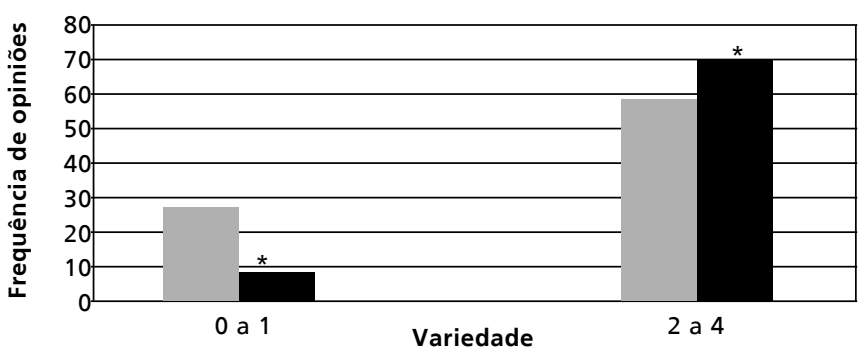

Mulheres sem filhos

aulheres com filhos

Conhecimento de variedade de verduras segundo a paridade materna

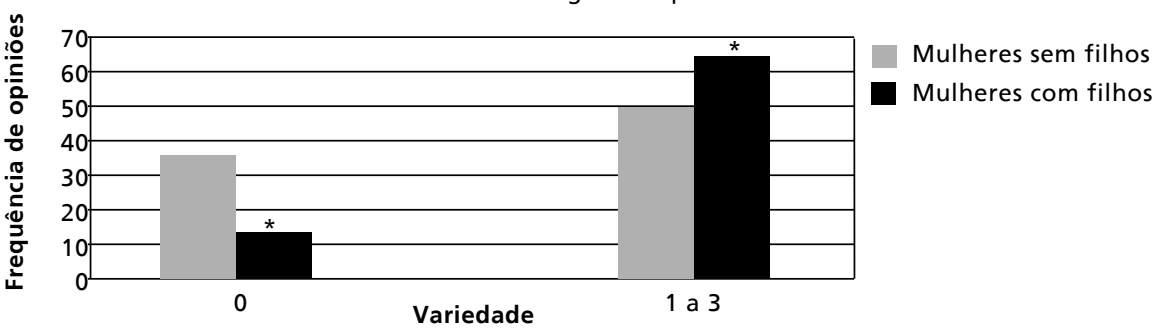

$* p<0,05$

Figura 3

Conhecimento de variedade de alimentos segundo a idade das gestantes de Centros de Saúde. São Paulo, Capital, 2002.

Conhecimento de variedade de carne segundo idade materna

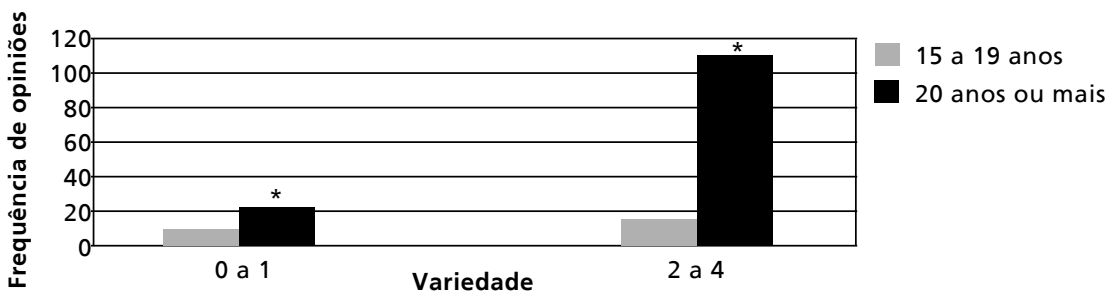

Conhecimento de variedade de verduras segundo idade materna.

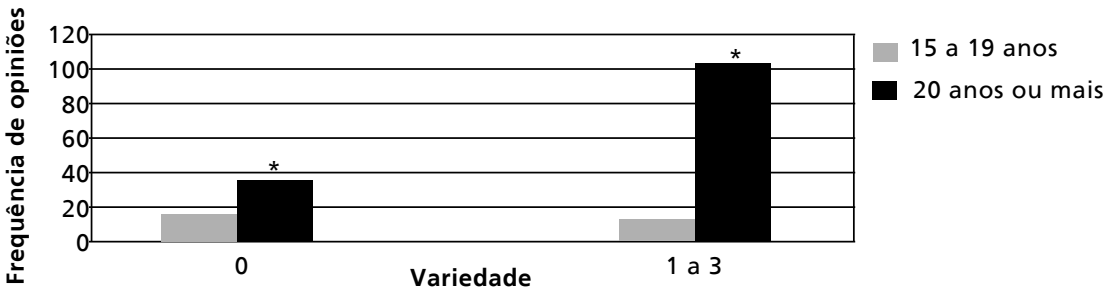




\section{Discussão}

A intenção freqüente de introduzir água e chá a partir do primeiro mês de vida, coincide com o período em que ocorre o estabelecimento da amamentação para a dupla mãe e filho. 18 A oferta de água para saciar a suposta sede do bebê durante a amamentação e o uso de chá para aliviar possíveis cólicas foi pretendida mesmo após elas terem recebido aconselhamento sobre amamentação exclusiva. O hábito de ofertar fluidos pouco nutritivos como água e chás em idade de amamentação exclusiva é prática comum em nosso meio e decorre, pelo menos, do período colonial quando as mulheres africanas que serviam como amas eram obrigadas a adotar dietas alternativas aos próprios filhos, tendo em vista que o leite materno era destinado aos filhos de europeus que aqui moravam. ${ }^{2}$

A intenção de oferta do chá mesmo para fins terapêuticos tem sido combatida em vários estudos. Euclydes 10 afirma que o chá além de não contribuir em nutrientes, ainda contem substâncias que comprometem a biodisponibilidade de minerais do leite materno. Para Percegoni, 23 ao saciar o apetite do bebê com estes líquidos, ocorre a redução da sucção de leite à mama, diminui a produção láctea na mãe, contribuindo para o declínio da amamentação. 24 Enquanto Marques et al.27 apontam que a intenção de ofertar água e chá desde a primeira semana de vida, como ocorreu no presente estudo, predispõe à introdução de outro leite.

Imediatamente após o desejo de oferecer água e chá, ocorreu entre elas o interesse pela oferta de suco de laranja no período que antecede ao sexto mês de vida. Apesar de o suco de frutas cítricas fornecer à dieta infantil elevado teor em vitamina $\mathrm{C}$, com o que eleva o aproveitamento de ferro da refeição salgada, convém que sua oferta tenha início aos seis meses de idade entre crianças amamentadas. Na dieta à base de leite de vaca, a oferta de suco cítrico pode ser necessária mais cedo. Em idade inferior ao sexto mês de vida, o consumo de suco de frutas esteve associado à cólica infanti121 e a introdução excessiva de líquidos, no mesmo período, tem sido relacionada à desidratação, 19,20 que se agrava quando, além dos líquidos, a criança recebe leite de outra espécie ou fórmula. 19,20

Euclydes 10 aponta que o grande inconveniente do consumo de leite de vaca antes dos seis meses de idade se deve à imaturidade renal em concentrar e eliminar o elevado teor de solutos que resultam do metabolismo desse alimento, requerendo adequadas técnicas de diluição. A alimentação com leite de vaca em idade precoce torna-se ainda mais crítica quando não se dispõe de condições sanitárias envolvendo sua manipulação. ${ }^{8}$ No presente estudo, a oferta de leite de vaca foi prevista por $39 \%$ das gestantes para ocorrer antes do sexto mês de vida e entre aquelas que pretendiam ofertar leite em pó integral não foi demonstrado conhecimento de técnicas de diluição sobre o leite reconstituído, apenas notou-se preocupação em ferver a água de preparo.

Dentre as mulheres que pretendiam introduzir outro leite, somente sete delas admitiram o interesse em procurar auxílio médico para a escolha do produto. Observou-se o fato delas não dissociarem o leite em pó do leite fluido. A maioria referiu-se à marca ou à embalagem do produto, existindo a valorização da mesma, possível influência da propaganda empreendida pela indústria de substitutos do leite materno. O interesse pelo leite em pó foi predominante para o primeiro semestre, por acharem mais apropriado para bebê, enquanto que o leite fluido foi identificado como alimento da família e sua introdução foi pretendida, com mais freqüência, para o final do primeiro ano de vida.

O interesse pela introdução de leite de vaca no primeiro ano de vida indica uma tendência constante ao desmame. Essa previsão se contrapõe ao tempo de duração incentivado pelas políticas de saúde em nosso país, na melhora da qualidade do estado nutricional infantil. 9 O desmame precoce e adoção de alimentação pela mamadeira torna propícia a desnutrição, sendo a ferro-deficiência um dos eventos que decorrem desta prática. Alimentação à base de leite de vaca tende a interferir com a biodisponibilidade de ferro da dieta, tanto pela predominância quanto pela concomitância de consumo. Em dieta com predomínio lácteo, a escassez em ferro do leite de vaca soma-se à redução de apetite da criança e à restrição de oferta de alimentos semi-sólidos possíveis fornecedores de ferro. Entre crianças no primeiro ano de vida, a introdução de carne na dieta não foi suficiente para melhorar a situação orgânica de ferro e constatou-se entre elas um elevado consumo de leite de vaca. 22 Substâncias presentes no leite de vaca, por razões bioquímicas, inibem o aproveitamento de ferro dos demais alimentos ingeridos na sua presença, colaborando para o diagnóstico de ferro-deficiência e anemia entre crianças no primeiro ano de vida. ${ }^{22}$ Para Hallberg et al., ${ }^{12}$ o maior teor em cálcio do leite de vaca, quando comparado ao leite humano, é um dos elementos que interfere negativamente na absorção de ferro na presença de leite de vaca, 12 mas o mesmo não ocorre quando os alimentos são ingeridos em simultâneo à amamentação, pois o leite materno apresenta elevada biodisponibilidade em ferro, podendo alcançar $49 \%$ de aprovei- 
tamento, ${ }^{11}$ o que o torna suficiente ao requerimento de ferro do lactente até o sexto mês de vida.11,12

Aos seis meses de idade a criança encontra-se em intenso crescimento e requer demanda adicional de ferro, ao mesmo tempo em que suas reservas orgânicas encontram-se reduzidas. ${ }^{11,12}$ Então passa a depender do contínuo e adequando suprimento de ferro da dieta e, ao mesmo tempo, fica vulnerável à deficiência, pois necessita de ferro para manter a concentração de hemoglobina de acordo com o volu-me de sangue em expansão,11,12 tornando prioritária a introdução de alimentos que sejam fontes de ferro, como o fígado, a carne, o peixe, o frango, o feijão e a gema de ovo cozida, 13 de preferência ofertados em combinações facilitadoras da absorção de ferro.

$\mathrm{Na}$ intenção materna, o frango foi a principal fonte de ferro-heme a ser utilizada na dieta infantil, mas $31 \%$ delas pretendiam introduzi-lo somente a partir do sétimo mês de vida, contribuindo com uma perspectiva de introdução de fontes de ferro tardia. A elevada recusa de oferta de peixe na dieta infantil traz como prejuízo, para a saúde da criança, a ausência de ácidos graxos poliinsaturados da série ômega-3, os quais participam da formação do sistema nervoso e do crescimento. 10,26 Embora não haja consenso na literatura sobre o melhor tempo de introdução de peixe, é desejável que sua oferta ocorra gradualmente a partir do sexto mês de vida, porém observou-se pouco interesse de oferta no primeiro ano de vida. O fígado, principal fonte de ferro, também foi muito rejeitado para a dieta infantil. A recusa observada em ofertar fígado e peixe pode ser resultado da falta de hábito materno em consumi-los. Em relação ao peixe, o aspecto geográfico do viver na cidade paulistana, distante do mar e inviável à pesca, pode ser um dos fatores que contribui para inibir o consumo. A introdução de peixe na alimentação infantil também pode estar envolta em mitos. Lopes 28 observou que a introdução de cação na dieta de crianças pequenas estava relacionada à crença, da comunidade, na capacidade do "tubarãozinho" despertar a fala.

Ainda em relação à oferta de alimentos ricos em ferro, constatou-se que gestantes com pelo menos um filho anterior apresentaram maior conhecimento de variedade de carnes, quando comparadas às gestantes sem filho anterior. Neste caso, a experiência com filho anterior pode contribuir para que a criança receba uma dieta mais variada em carne, com duas ou mais opções. O conhecimento diversificado de carnes pode ser favorecido pelos anos de vida, pois gestantes adultas conheciam mais variedades de carnes, quando comparadas às gestantes adoles- centes. Estudo realizado para verificar diferenças na dieta de filhos de mulheres adolescentes e adultas, também observou que os filhos de adolescentes ingeriram menos carne quando comparados aos filhos de adultas. 25 Os anos de estudo não resultaram em melhor conhecimento de variedade de carnes, nem de nenhuma outra variedade de alimento investigada, contrariando a informação de que a escolaridade poderia favorecer a ampliação do conhecimento. 24

A intenção de ofertar ovos cozidos a partir do $10^{\circ}$ mês de vida se mostrou adequada em relação ao tempo sugerido por Ctenas e Vítolo ${ }^{15}$ para proceder à introdução de clara, evitando-se riscos de alergias. O interesse pela cocção de ovos também foi acertado, pois além de prevenir salmonelose, otimiza a digestibilidade da proteína, por meio da coagulação, e aumenta a biodisponibilidade do ferro da gema, pela inativação de enzimas. A presença de colesterol, tido como prejudicial à saúde da criança, motivou o receio do pequeno grupo que não pretendeu incluir ovos na dieta infantil. Contudo, o colesterol é fundamental ao organismo da criança, pois participa da composição do tecido nervoso, das membranas celulares, dos hormônios e da vitamina A, 10,26 podendo ser encontrado no leite materno e na gema de ovo cozida. $\mathrm{O}$ argumento materno contrário à oferta de ovos à criança indica que as orientações nutricionais dirigidas a elas, durante o pré-natal, foram transmitidas ou aprendidas sem distinção de requerimentos nutricionais entre adultos e crianças.

A introdução de feijão tende a ocorrer ainda no primeiro ano de vida e foi semelhante ao verificado em outro estudo. $22 \mathrm{~A}$ intenção de ofertar o feijão na dieta foi mais freqüente a partir do $10^{\circ}$ mês de vida, comportamento adequado por se tratar de alimento de consumo familiar. O feijão constitui a mais importante fonte de ferro não-heme, o que o torna importante para a dieta de crianças brasileiras, de preferência, associado às frutas e hortaliças e à carne vermelha, cuja combinação eleva a biodisponibilidade de ferro dessa leguminosa, em até $85 \% .12$ Sua oferta combinada ao arroz, como a pretendida pelas gestantes deste estudo, obtém melhor digestibilidade em proteínas, aumentando o valor biológico das mesmas. 14

No presente estudo, a intenção de introduzir alimentos semi-sólidos caracterizou-se pela oferta de polpas de frutas e de legumes cozidos e correspondeu à modificação da consistência da dieta aos seis meses, passo importante para estimular a mastigação na criança. A introdução de alimentos complementares sob a consistência semi-sólida foi relacionada a maior duração do aleitamento materno, quando comparadas às crianças que receberam 
inicialmente alimentos de consistência líquida durante amamentação.18 Embora tenha ocorrido, nesta população, previsão de início da alimentação complementar a partir da consistência líquida, a modificação da dieta prevista com a oferta de frutas e legumes, com mais freqüência aos seis meses de idade, pode ser considerada apropriada, dentre outras razões, pela fácil digestibilidade, boa densidade energética 10 e sabor agradável ao paladar infantil, viabilizando a introdução de outros alimentos.

A popularidade de frutas e de legumes foi um dos aspectos positivos do estudo, pois todas as mulheres, incluindo adolescentes e nulíparas, conheciam pelo menos uma variedade de fruta e de legume. Vieira et al.25 também constataram não haver diferença estatisticamente significante no consumo de frutas e legumes entre filhos de adolescentes e de adultas.

Ainda em relação aos legumes, outro aspecto observado foi o freqüente interesse materno pela oferta de beterraba, por considerá-la alimento "forte", muito rico em ferro. Costa, 29 em pesquisa com operários, observou que os alimentos considerados "fortes" eram sempre aqueles que se aproximavam da tonalidade vermelha, existindo uma conotação com o sangue e, portanto, com a capacidade de dar "força" ao organismo, enquanto que alimentos claros eram comparados à fraqueza e à doença. De acordo com Boltanski, 5 alimentos popularmente considerados "fortes" são mais consumidos entre pessoas da classe social de menor condição socioeconômica, enquanto alimentos tidos como "fracos" são mais aceitos pela classe social de maior condição socioeconômica. Outros estudos são necessários para apurar a relação entre cor do alimento e representação de "força" entre indivíduos de diferentes classes sociais. No presente estudo, o conceito de alimento "forte" atribuído à beterraba pode contribuir com sua introdução de forma abundante no primeiro ano de vida. No entanto, esta hortaliça, além de escassa em ferro, devido à presença de nitrato em sua composição, é implicada na metahemoglobinemia. Para Zeman et al. 16 essa desordem decorre da baixa acidez do estômago de bebês que facilita a ação de bactérias que convertem o nitrato do alimento em nitrito que absorvido age na hemoglobina. Evento este relatado mesmo entre crianças com mais de seis meses de idade. ${ }^{16,17}$

A intenção de introduzir verduras na dieta infantil foi muito pouco freqüente na opinião materna, mas esta minoria pretendia submetê-las à cocção e isto se mostrou adequado para adaptá-las à capacidade digestiva da criança e eliminar eventuais agentes infecciosos, tornando-as seguras ao consumo no pri- meiro ano de vida. A cor 26 foi o critério adotado para atribuir às verduras verde-escuras um maior teor em ferro. Apesar do grupo de verduras verde-escuras constar na literatura 9 como exemplo de fonte de ferro, a escassez e a baixa biodisponibilidade do mesmo, 13 comprometem o consumo de verduras como fontes desse micronutriente.

A valorização do consumo de verduras verdeescuras pode ser atribuída à popularização do espinafre através do personagem de desenho animado Popeye, cuja aceitação pública foi tão grande que elevou de forma considerável o consumo de espinafre no mundo. ${ }^{30}$ No entanto, a cor verde brilhante de verduras indica a presença de complexos formados com cobre, seguramente não absorvidos pelo organismo humano. 26 Assim, durante a orientação nutricional, as mulheres precisam ser informadas que verduras não substituem o consumo de fontes seguras de ferro. A equipe de saúde pode recorrer a outros atrativos na formação do hábito materno em ofertar verduras na dieta infantil. Atualmente, pigmentos encontrados em verduras verde-escuras 26 estão sendo relacionados à saúde ocular. As mulheres que não pretenderam incluir verduras na dieta da criança recorreram à falta de hábito próprio em consumi-las ou consideraram suficiente apenas o uso de ervas aromáticas. Na falta de costume de comer verduras, a vida em centro urbano também interfere pela falta de terra, reduzindo o cultivo de hortaliças.

Gestantes adolescentes e nulíparas demonstraram menor conhecimento de variedade de verduras quando comparadas às gestantes adultas e com filho anterior. A presença de filho anterior representou maior oportunidade de aprender pela experiência ou pelo acesso às informações obtidas em pediatria, portanto confirmou o que pressupôs este estudo. A dieta prevista por gestantes adolescentes e nulíparas tende a ser menos variada do que a dieta pretendida pelas mulheres adultas e com filho anterior. Dietas monótonas são insuficientes para garantir nutrição adequada à saúde e ao crescimento da criança, ao passo que uma boa variedade de alimentos contribui para o desenvolvimento, atraindo a atenção da criança à descoberta do meio ambiente pelo contato com novas texturas, aromas e sabores das preparações, além de encorajá-la à socialização.

A perspectiva da dieta infantil obtida com gestantes possibilitou reafirmar a importância de se discutir a transição alimentar durante a assistência prestada à mulher, tendo em vista a possibilidade de muitas delas optarem por introduzir alimentos antes da primeira consulta à pediatria. Dieta aprendida por conta própria pela falta de acolhimento da equipe de saúde pode favorecer riscos à saúde da criança no início da vida. 


\section{Agradecimentos}

Ao Conselho Nacional de Pesquisa (CNPq), pela concessão de bolsa de estudo. Ao Centro de Saúde Geraldo de Paula Souza e ao Centro de Saúde Escola Barra Funda, pelo acesso às usuárias. Às gestantes pela cooperação.

\section{Referências}

1. Turano W, Almeida CCC. Educação nutricional. In: Gouveia ELC. Nutrição, saúde e comunidade. Rio de Janeiro: Revinter;1999. p.57-77.

2. Freyre G. Casa-grande e senzala. Rio de Janeiro; Record; 2000.

3. Novaes HMD. A puericultura em questão [dissertação de mestrado]. São Paulo: Faculdade de Medicina da Universidade de São Paulo; 1979.

4. Vieira EM. A medicalização do corpo feminino. In: Giffin $\mathrm{K}$, Costa SH. Questões da saúde reprodutiva. Rio de Janeiro: Fiocruz; 1999. p.67-91.

5. Boltanski L. As classes sociais e o corpo. Rio de Janeiro: Graal; 1979.

6. Züñiga HPP, Monteiro CA. Uma nova abordagem para a ascensão da mortalidade infantil da cidade de São Paulo nos anos 60. In: Velhos e novos males da saúde no Brasil: Evolução do país e de suas doenças. São Paulo: Hucitec, Nupens; 2000. p.157-72.

7. Batista LE. Alguns aspectos das políticas de saúde da mulher no Brasil - o PAISM: um estudo de caso. In: Scavone L, Batista LE. Pesquisas de gênero: entre o público e o privado. Araraquara: Laboratório Editorial; 2000. p. 49-67.

8. WHO (World Health Organization). Expert consultation on the optimal duration of exclusive breastfeeding: conclusions and recommendations. Geneva; 2001. (Document A54 INF.DOC./4).

9. Ministério da Saúde. Secretaria de Políticas de Saúde. Guia alimentar para crianças menores de dois anos. Brasília (DF); 2002.

10. Euclydes MP. Nutrição do lactente: base científica para uma alimentação adequada. Viçosa: Universidade Federal de Viçosa; 2000.

11. Lönnerdal B. Regulation of mineral and trace elements in human milk: exogenous and endogenous factors. Nutr Rev 2000; 58: 223-9.

12. Hallberg L, Hoppe M, Andersson M, Hulthén L. The role of meat to improve the critical iron balance during weaning. Pediatrics 2003; 111: 864-70.

13. Kasdam TS. Terapia clínica nutricional para a anemia. In: Mahan LK, Escott-Stump S. Krause Alimentos nutrição e dietoterapia. São Paulo: Roca; 2002. p. 756-74.

14. Kannan S, Nielsen SS, Mason AC. Protein digestibilitycorrected amino acid scores for bean and bean-rice infant weaning food products. J Agric Food Chem 2001; 49: 5070-4.
15. Ctenas MLB, Vítolo MR. Crescendo com saúde: o guia de crescimento da criança. São Paulo: C2 Ed; 1999.

16.Zeman CL, Kross B, Vlad M. A nested case-control study of methemoglobinemia risk factors in children of Transylvania, Romania. Environ Health Perspect 2002; 110: $817-22$

17. Sanchez-Echaniz J, Benito-Fernández J, Mintegui-Raso S. Methemoglobinemia and consumption of vegetables in infants. Pediatrics 2001; 107: 1024-8.

18. Bueno MB, Souza JMP, Paz SMRS, Souza SB, Cheung PPY, Augusto RA. Duração da amamentação após a introdução de outro leite: seguimento de coorte de crianças nascidas em um Hospital Universitário em São Paulo. Rev Bras Epidemiol 2002; 5: 145-52.

19. Bruce RC, Kliegman RM. Hyponatremic seizures secondary to oral water intoxication in infancy: association with commercial bottled drinking water. Pediatrics 1997; 100: 4 .

20. Banajeh SM, Hussein RF. The impact of breastfeeding on serum electrolytes in infants hospitalized with severe dehydrating diarrhoea in Yemen. Ann Trop Paediatr 1999; 19: 371-6.

21. Duro D, Rising R, Cedillo M, Lifshitz F. Association between infantile colic and carbohydrate malabsorption from fruit juices in infancy. Pediatrics 2002; 109: 797-805.

22. Martins M. A orientação alimentar e a deficiência de ferro em lactentes [tese doutorado]. São Paulo: Faculdade de Saúde Pública da Universidade de São Paulo; 2002.

23. Percegoni N, Araújo RMA, Silva MMS, Euclydes MP, Tinoco ALA. Conhecimento sobre aleitamento materno de puérperas atendidas em dois hospitais de Viçosa, Minas Gerais. Rev Nutr 2002; 15: 29-35.

24. Giugliani ERJ, Rocha VL, Neves JM, Polanczyk CA, Seffrin CF, Susin LO. Conhecimentos maternos em amamentação e fatores associados. J Pediatr [Rio J] 1995; 71: 77-81.

25. Vieira LF, Pinto e Silva JLC, Barros Filho AAB. A amamentação e a alimentação complementar de filhos de mães adolescentes são diferentes das de filhos de mães adultas? J Pediatr [Rio J] 2003; 79: 317-26.

26. Bobbio FO, Bobbio PA. Introdução à química de alimentos. São Paulo: Varela; 2003.

27. Marques NM, Lira PIC, Lima MC, Silva NL, Batista Filho M, Huttly SRA, Ashworth A. Breastfeeding and early weaning practices in Northeast Brasil: a longitudinal study. Pediatrics 2001; 108: e66. Disponível em URL: http://www.pediatrics.org [2003, maio, 20]. 
28. Lopes SMB. Cultura, linguagem, fonoaudiologia; uma escuta do discurso familiar no contexto da Saúde Pública.[dissertação de mestrado]. São Paulo: Faculdade de Saúde Pública da Universidade de São Paulo; 2001.

29. Costa AM. Riqueza de pobre: um estudo em antropologia da saúde [dissertação de mestrado]. Brasília (DF): Universidade de Brasília; 1980.
30. Crystal City, TX. The handbook of Texas. Disponível em URL: http://www.tsha.utexas.edu /handbook/online/articles/view/CC/hfc17.html [2003, maio, 20].

Recebido em 23 de setembro de 2004

Versão final apresentada em 3 de fevereiro de 2006 Aprovado em 20 de fevereiro de 2006 